\title{
EEN EN ANDER OVER DE MOLUKKEN-PUBLICATIE VAN 1824.
}

\author{
DOOR
}

Dr. F. W. STAPEL.

Toen na de honderd dagen Napoleon voor goed van het staatstooneel was verdwenen, konden de groote mogendheden overgaan tot uitvoering der besluiten van de Londensche Conventie van 1814, waartoe ook behoorde de teruggave der door de Engelschen bezette koloniën aan Nederland. Koning Willem I belastte de Commissarissen-Generaal Elout, Buyskes en Van der Capellen met de overname, en droeg hun tevens op het bestuur opnieuw te regelen, waartoe zij van een uitvoerige instructie werden voorzien. De laatste alinea van artikel 19 dier instructie luidde :

„Ten aanzien der nagelen, op Ambon en daar omstreeks ,,ingezameld wordende, zullen zij speciaal moeten onderzoeken, ,of en waarom derzelver monopolie voor den Staat voor, deeliger moet geacht worden dan het aanmoedigen van den „landbouw door eene vrije vaart en het percipiëren van grond,lasten en in- en uitgaande regten”.

Aan dit deel van hun opdracht hebben C. C. G. G. niet voldaan. De overname van het uitgestrekte gebied, de regeling der financiën, met de taxatie der over te nemen goederen, vorderingen en verplichtingen, het onderzoek naar de werking van het Landrentestelsel, het herstel van het geschokte prestige van het Nederlandsche Gouvernement, en dit alles onder de tegenwerking van Raffles, nam hen zoodanig in beslag, dat voor de regeling van verschillende detailkwesties geen tijd beschikbaar bleef. Zij moesten de overneming van de meeste buitenposten zelfs aan anderen delegeeren en, voor wat'de Molukken betreft, wezen zij 31 December 1816 daartoe aan den bekenden Nicolaas Engelhard ${ }^{1}$ ) en den ambtenaar J. A. van Middelkoop, welke

1) Zie voor hem Dr. F. DE Hads, Priangan I, (personalia) blz. 77-87. 
laatste als gouverneur zou optreden. Den 25sten Maart d.a.v. droeg de Engelsche gouverneur Martin hun de residentie Ambon over; 2 April volgde Banda.

$\mathrm{Na}$ den overgang van de bezittingen der Compagnie aan de Bataafsche Republiek, was in de Molukken de verplichte levering der specerijen van kracht gebleven, en het Staatsmonopolie verschilde in beginsel en praktijk niets van dat der Compagnie; zelfs de betaling door middel van lijnwaden bleef gehandhaafd. Ook de Engelschen hadden tijdens hun interregnum het stelsel niet opgeheven, maar wel met groote soepelheid toegepast. Toen nu in 1816 het Nederlandsche bestuur hersteld werd, vreescle de bevolking een terugkeer tot de strenge handhaving van het monopolie, zooals zij zich dat uit den Compagniestijd herinnerde; zij werd, door het ontactisch optreden van Engelhard en Van Middelkoop, in die meening versterkt. Dit leidde tot den opstand, die in Mei 1817 op Saparoea uitbrak, en die zich weldra uitbreiddle over de geheele residentie Ambon. Een krachtdadig optreden van Buyskes was noodig om de rust te herstellen, waarna de verplichte levering van alle kruidnagelen, voor een groot deel in ruil voor lijnwaden, gehandhaafd bleef. Van Middelkoop moest plaats maken voor generaal De Kock.

Tijdens den opstand had Van der Capellen een byzondere belangstelling betoond voor de werking van het Moluksche stelsel en den invloed daarvan op de bevolking. Toen hij, na het vertrek van Elout $\epsilon n$ Buyskes, als Gouverneur-Generaal het hoogste bewind had aanvaard, was een zijner eerste maatregelen het instellen van een Molukken-commissie, bestaande uit de heeren Mr. H. J. van de Graaff en G. F. Meylan. In hun in 1821 ingediend rapport spraken deze heeren de meening uit, dat de toestand der bevolking onder het vigeerende stelsel zeer ongunstig was; zij adviseerden tot afschaffing van het monopolie, en aanmoediging van kolonisatie door Europeesche landbouwers, om de specerijen in vrij bedrijf aan te kweeken.

Het oordeel dezer commissie, voor wat aangaat den ellendigen toestand der bevolking, werd geheel onderschreven door den gouverneur der Molukken, Mr. P. Merkus, nadat hij in 1823 was teruggekeerd van een inspectiereis door zijn geheele gewest.

Alvorens in deze een besluit te nemen, besloot Van der Cappellen zich nog eerst persoonlijk ter plaatse op de hoogte te gaan stellen. Daartoe begaf hij zich in den aanvang van 1824 met Van de Graaff 
naar Ambon, waar zij, in gezelschap van Merkus, opnieuw een uitgebreid onderzoek instelden. ${ }^{1}$ ) Dit bracht Van der Capellen tot het inzicht, dat een algeheele afschaffing van het monopolie noodzakelijk was, zoowel in het belang der bevolking als in dat van den Lande, doch hij achtte zich niet gerechtigd een zoo belangrijke principieele beslissing te nemen zonder een uitvoerige bespreking der consequenties in de voltallige vergadering der Hooge Regeering. Wel meende hij al aanstonds maatregelen te moeten treffen tot wegneming van den ergsten druk, en het zijn deze maatregelen, welke in de Molukkenpublicatie van 1824 werden vastgesteld en, in Hollandschen zoowel als Maleischen tekst, onder de bevolking verspreid. Men vindt dit merkwaardige stuk in Staatsblad 1824, No. 19a. Het begint met de erkenning, dat het lot der bevolking nog beklagenswaardiger gebleken is, ,dan Wij Ons hadden kunnen voorstellen”, en bepaalt o.a. dat voor den verplichten arbeid het dubbele zal worden vergoed, van hetgeen tot nu toe werd betaald; dat leveringen en diensten-omniet zijn afgeschaft en dat geen hongie-tochten meer zullen plaats hebben.

In zijn hiervóór genoemd Journaal schrijft Van der Capellen, na de publicatie te hebben besproken: „Den Koning heb ik met ,,mijne verrigtingen te Amboina bekend gemaakt, en Z. M. niet ver,borgen, dat nu het monopoliestelsel niet meer in stand te houden ,.zal wezen. Hetzelfde heb ik aan den graaf G. K. van Hogendorp ${ }^{2}$ ) „geschreven, met toezending mijner publicatie."

Het zal stellig niet de minste geweest zijn der vele teleurstellingen, die Van der Capellen gedurende zijn Indische loopbaan heeft ondervonden, dat het Opperbestuur van een opheffing van het monopolie voorshands niets wilde weten. Nog geen volle maand, vóórdat de publicatie te Ambon was afgekondigd, hadden de vertegenwoordigers der moederlandsche regeering het Tractaat van Londen onderteekend, waarbij o.m. aan de onderdanen van beide contracteerende staten vrije vaart en handel in elkanders koloniën werden gegarandeerd, ,de „Moluksche eilanden, en speciaal Ambon, Banda en Ternate met ,,derzelver onmiddellijke onderhoorigheden uitgezonderd, tot tijd en ,wijle het Nederlandsch Gouvernement raadzaam oordeelen zal van

1) Zie vooral het Journaal van den baron Van der Capellen op zijne reis door de Molukko's, afgedrukt in het Tijdschrift voor Nederlandsch-Indië, 1855, deel II.

2) Gijsbert Karel gold, na den steun, dien hij verleend had aan de denkbeelden van zijn broeder Dirk, voor een der meest verlichte koloniale politici. 
„den alleenhandel in specerijen af te zien”. Hiermede was het lot van Van der Capellen's voorstel beslist; het heeft tot 1864 geduurd, eer de aanplant en verkoop van specerijen geheel vrij werden.

De Molukken-publicatie zal steeds haar waarde behouden als het eerste of ficieele staatsstuk, waaruit een nieuwe geest spreekt. Haar redactie wijkt in dit opzicht van alle vroegere staatsstukken af, dat zij de openlijke erkenning bevat, dat de tot dusver gevolgde politiek verderfelijk voor de bevolking was.

De waardeering van zoodanige openhartigheid is, gelijk men begrijpen zal, zeer uiteenloopend geweest. De Luitenant-GouverneurGeneraal De Kock voelde er de grootste bewondering voor; een (anoniem) ambtenaar plaatste bij de publicatie de kantteekening: ,indien de bevolking ze had kunnen begrijpen, zou ze veel kwaad ,hebben gesticht."

Het heeft velen geinteresseerd, wie de opsteller van dit befaamde stuk is geweest. In een correspondentie, daarover in 1918 gevoerd tusschen wijlen P. H. van der Kemp en Prof. Mr. C. van Vollenhoven, verklaarde eerstgenoemde van meening te zijn, dat Mr. Van de Graaff het stuk zou hebben geredigeerd, terwijl laatstgenoemde in Mr. P. Merkus den auteur zag. Naar dezerzijdsche meening is zonder eenigen twijfel Van de Graaff de opsteller geweest. Een eerste aanwijzing daarvoor geeft de publicatie zelf; deze bevat namelijk den volgenden passus:

,Wij hebben in dengeen, dien Wij het opperbestuur over „u hebben toebetrouwd, en die met Onzen wil en met Onze ,bedoelingen bekend is, eenen waarborg voor de zachtheid en „lankmoedigheid, met welke verongelijkten zullen worden ,,aangehoord ....".

Het is moeilijk aan te nemen, dat gouverneur Merkus een zoodanig judicium over zichzelf zou hebben neergeschreven. Maar er is meer. In het reeds eenige malen genoemde Journaal van Van der Capellen leest men, onder 15 April (blz. 301):

„Op heden zijn de konferentiën met den heer $V$ an de „Graaff en den gouverneur Merkis afgeloopen, en de ,organieke stukken voor de residentie Amboina gearresteerd. „Zij bestaan uit eene publicatie, gerigt aan alle ingezetenen ,$\ldots$ en uit een reglement op het binnenlandsch bestuur en „,dat der financiën in de residentie Amboina....... Den 
„raad van Indië $\operatorname{Van}$ de Graaff, die zich met de redaktie ,,der stukken belast heeft, ben ik veel dank schuldig”.

Bij een onderzoek naar het auteurschap had Van der Kemp op het Rijksarchief een stuk gevonden, dat de overwegingen bevat, welke tot de Molukken-publicatie hebben geleid, ${ }^{1}$ ) een soort considerans dus. Hij maakte er een afschrift van, met het doel dat te publiceeren, doch door een voor schrijver dezes onbekende oorzaak is dit niet geschied. Als het thans volgt, is dat niet alleen om het stuk zelf, maar tevens als een posthume hulde aan den ijverigen geschiedvorscher, die Van der Kemp was.

F. W. S.

\section{AMBOINA.}

Overwegingen van het Besluit van den G. G. van 15 April 1824, No. 1. (Stbl. No. 19a).

Naar aanleiding van het besluit van den 7 January 1.1. No. 1 nader in overweging genomen zijnde

a. het rapport van de Commissie, bij resolutie van den 4 September 1820 No. 3 speciaal belast om in de Molukkos een naauwkeurig onderzoek te bewerkstelligen en van derzelver bevindingen een beredeneerd verslag te doen omtrent de zaken, vermeld bij het laatste gedeelte van art. 19 der instructie van Commissarissen-Generaal, bij 's Konings besluit van den 5 January 1815 gearresteerd:

„Ten aanzien der nagelen, op Ambon en daar omstreeks ingezameld wordende, zullen zij speciaal moeten onderzoeken of en waarom derzelver monopolic voor den staat voordeeliger moet geacht worden dan het aanmoedigen van den landbouw door eene vrije vaart en het percipieren van grondlasten en in- en uitgaande regten"

welk rapport

door den Gouverneur-Generaal om consideratiën en advies is gesteld geworden in handen van de Raden van Indië Muntinghe en D'Ozij, doch waarop door gemelde Raden niet is gediend geworden en waaromtrent de dispositie ten laatste tot het persoonlijk aanwezen van den Gouverneur-Generaal in de Molukkos is aangehouden;

b. het rapport van den Gouverneur der Molukkos d.d. 21 Mei 1823 (secreet), houdende een algemeen verslag van zijne bevinding op Amboina; en

1) Zie R. A., „Koloniën na 1813” bundel 966. 
c. het rapport van den Gouverneur voornoemd in dato 18 September 1823 (secreet) omtrent de onlangst door hem bezochte residentiën van Ternate en Banda.

En uit alle deze stukken, zoowel als uit het persoonlijk onderzoek van den Gouverneur-Generaal gedurende deszelfs aanwezen alhier, mitsgaders uit de conferentiën over de in gemelde stukken vervatte berigten en voorstellen herhaaldelijk alhier met den Raad van Indië Mr. H. J. van de Graaff en den Gouverneur der Molukkos-eilanden Mr. P. Merkus gehouden, ten volle gebleken zijnde,

dat alle gevoelens zich vereenigen, dat het monopoliestelzel van het Gouvernement in de specerijen, zoo als het tot dusver in de Moluksche eilanden Amboina, Banda, Ternate en onderhoorigheden is in staat gehouden, niet langer kan noch behoort te blijven bestaan, niet alleen in het belang der bevolking, welke daaronder sedert twee eeuwen bitter is gedrukt geworden, maar ook in het wezenlijk belang van den Lande;

dat dit gevoelen in de voorhandene stukken gegrond wordt:

op de onmogelijkheid om, sedert dat de vaart in de Moluksche zeeën voor vreemde natiën is opengezet, al de maatregelen, tot handhaving van het monopoliestelzel vereischt, ten uitvoer te leggen, speciaal om de onzedelijke extirpatie der specerijboomen in de geheele uitgestrektheid dezer bezittingen (met uitzondering der weinige eilanden, alwaar de specerijteelt gewettigd en aangehouden is) bij voortduring en in derzelver ganschen omvang te doen plaats hebben;

op de groote kosten van bestuur, toezigt en verdediging, welke van het bestaande stelsel onafscheidenlijk zijn, vermits de belangen der geheele bevolking lijnregt strijdig zijn met de vorderingen van het Gouvernement;

op de jaarlijks verminderende inkomsten, welke het Gouvernement der.Molukkos oplevert, daar de prijs der specerijen bij voortduring daalt, zoowel op de Indische als Europeesche markten, het natuurlijk gevolg der overbrenging van de specerijboomen naar plaatsen buiten Nederlandsch-Indie gelegen, byzonder gedurende den tijd, dat de Moluksche cilanden in het bezit der Engelschen zijn geweest, en op het hieruit geboren wordend vooruitzigt, dat de Moluksche cilanden, in plaats van eene winstgevende bezitting voor het vaderland te zijn, een drukkende last voor de Indische finantiën staan te worden;

dat wijders zoowel de Kommissie als de Gouverneur der Moluksche cilanden overeenkomen, niet alleen omtrent de onvermijdelijke noodzakelijkheid, om onder deze omstandigheden bijtijds indachtig te zijn 
op het invoeren van een doelmatiger stelzel van bestuur voor deze gewesten, meer overeenstemmende met de beginzelen, op welke in het algemeene de Regering in N. I. thans gevestigd is, met de billijkheid ten aanzien der reeds te lang onder het monopoliestelzel gebukt gaande bevolking, en met de welbegrepene en duurzame belangen van het Gouvernement, maar ook in het gevoelen, dat de bedoelde verandering moet bestaan in eene geheele opheffing van het vigerend monopoliestelzel, en het daarstellen in deszelfs plaats van een stelzel van vrijen handel en vrije cultuur, gegrond op regelmatige belastingen tot goedmaking der onkosten van een behoorlijk politiek en finantieel bestuur - dat echter in de wijze, om dit doel te bereiken en de middelen, tot dat einde in het werk te stellen, de meeningen verschillend zijn, daar de Kommissie geoordeeld heeft de nieuw in te voeren inrigtingen door voorbereidende en op tijd werkende maatregelen te moeten doen voorafgaan, terwijl de Gouverneur der Molukkos van meening is geweest, dat de veranderingen reeds dadelijk zouden kunnen worden ingesteld en uitgevoerd, hebbende bovendien de Kommissie in haar overzigt der gevolgen van de opheffing van het monopolie alle, of ten minste de voornaamste landen, onder het Moluksche Gouvernement behoorende, begrepen en tevens, hoezeer als een meer verwijderd doel, ook de intrekking van den alleenhandel op de Bandasche eilanden toegepast, terwijl de Gouverneur in zijne beschouwing het monopolie der notenmuskaat op de Bandasche eilanden (als van een geheel byzonderen aard) heeft gehouden;

dat in de keus tusschen deze twee opiniën, welker adoptie in elk geval gedurende eenige jaren beduidende opofferingen in geld zal vorderen, aan de eene zijde in aanmerking komt, dat bij het omhelzen der voorstellen van de Kommissie wel alle maatregelen gaandeweg de strekking zullen moeten hebben, om direct of indirect tot het erkende doel te leiden, maar dat het Gouvernement telkens geene enkele schrede verder zal behoeven te gaan dan deszelfs verkregen kennis en de op het oogenblik beschikbare middelen zullen toelaten, terwijl het tevens volkomen in staat zal zijn om jaarlijks de opofferingen, die het tot bevordering van het doel wil en kan doen, vooraf te bepalen, maar dat het aan den anderen kant geene mindre overweging verdient, dat onder de voorschreven maatregelen de zoo onvermijdelijk geacht wordende hervorming van het stelsel van bestuur slechts eenen zeer langzamen tred zal kunnen gaan; dat de handel, die alleen de van-een gereten banden tusschen de verspreid liggende volken van den Molukschen archipel onderling, èn tusschen die vol- 
ken, èn de overige onderdanen van het Gouvernement herstellen kan, bij voortduring en zoo lang het monopoliestelzel staat, de beperkingen, welke dat stelzel vereischt, zal blijven gevoelen en alzoo de stremming, welke die beperkingen in een vrij en onbelemmerd verkeer moeten veroorzaken, zal blijven ondervinden, en dat mitsdien ook op weinig of geen medewerking van de zijde der bevolking te hopen is, daar zij zelf in de maatregelen, eeniglijk in haar eigen belang daargesteld, meer het onaangename der nieuwigheid, dan het heilzame van het doel zoude bespeuren;

dat leiding, aanmoediging en overreding alleen dus niet genoegzaam zullen zijn, maar bij voortduring door dwangmiddelen ondersteund zullen moeten worden, waarbij vooreerst althans aan geene vermindering van krijgsmagt gedacht zou kunnen worden en gevolgelijk de geldelijke opoffering, hoezeer voor het oogenblik ongevoeliger, op den duur, en berekend over den tijd, dien de voorbereidende maatregelen zullen vorderen, aanzienlijker zullen zijn, dan bij eene dadelijke verandering van het stelzel met grond zou kunnen worden verwacht, terwijl nog, onverminderd de vorenstaande bedenkingen, in aanmerking komt, dat vooral in deze gewesten onder de meer dan elders afwisselende besturen, alle maatregelen, welke een aanhoudend geduld vorderen, door volharding in doel en middelen alleen tot stand kunnen gebragt worden en op langen tijd werken;

dat daarentegen aan den anderen kant de dadelijke geheele en onherroepelijke vernietiging van het monopoliestelzel met al de ruime en heilzame middelen, daarmede in verband staande, terstond eene weldadige uitwerking op het lot der bevolking zal uitoefenen, welke door die bevolking onmiddelijk gevoeld en ondervonden wordende, derzelver medewerking tot bereiking van 's Gouvernements doeleinden zal opwekken, alle reactie, uit strijdige belangen geboren, zal doen ophouden en al dadelijk eene vermindering van krijgsmacht en besparing van uitgaven ten gevolge zal hebben;

dat deze ontwikkelingen en overwegingen, gevoegd bij de gelegenheid, waarin zich de Gouverneur-Generaal sedert eenige weken heeft bevonden, om zich met al het grievende, hetwelk in het thans bestaande stelzel voor de bevolking der Moluksche eilanden onvermijdelijk gelegen is, persoonlijk bekend te maken, zoowel als met de onregtvaardigheid en onredelijkheid der middelen, tot instandhouding van hetzelve gebezigd zijnde en bij voortduring vereischt wordende, dan ook aan den Gouverneur-Generaal de volle overtuiging hebben gegeven, dat dit stelzel van onderdrukking onbestaanbaar is met de 
persoonlijke denkwijze des Konings, zoowel als met de beginselen, op welke Zijne Majesteit verlangd heeft, dat deszelfs bestuur in Indië in het algemeen zou wezen gevestigd; dan dat, hoezeer de Gouverneur-Greneraal door deze overtuiging geleid, reeds nu volkomen bereid en genegen zoude zijn om alle deze bezwaren onverwijld uit den weg te ruimen en zich te vereenigen met de voorstellen tot intrekking van den uitsluitenden handel in kruidnagelen, met al de gevolgen van dien, daartegen echter de bedenkingen bestaan, in de eerste plaats, dat het wenschelijk is, dat tot zoodanigen hoogst gewigtigen stap niet worde overgegaan, dan met overleg van al de leden der Hooge Regeering, ten einde ook door de consideratiën, welke zij te dezen angaande zullen suppediteren, over deze zaak al dat licht te verspreiden, waarvoor dezelve slechts eenigermate vatbaar is; en in de tweede plaats, dat de korte tijd, welke de Gouverneur-Generaal nog voor deszelfs verblijf te dezer plaats kan afzonderen, ongenoegzaam is, om dadelijk te voorzien in al de maatregelen, welke eene geheele verandering en buiten werking stelling van het monopoliestelzel zoude noodzakelijk maken;

dat evenwel eene onverwijlde voorziening in de drukkendste bezwaren, aan welke de bevolking onder de bestaande inrigtingen onderhevig is, ook zonder eene onmiddelijke opheffing van het monopoliestelzel, onvermijdelijk noodzakelijk is geworden, zoowel tot eene dadelijke verbetering van het lot der bevolking, als om aan die bevolking reeds nu terstond metderdaad te toonen, dat derzelver belangen door het Gouvernement ernstig ter harte zijn genomen, en ten einde dezelve van stonde aan wordt opgeheven uit den staat van ontmoediging, onder welken zij, als een gevolg van het stelzel van geweld en onderdrukking, reeds sedert zoolang gebukt heeft gegaan, terwijl afgescheiden daarvan de buitengewone omstandigheid des aanwezens van den Gouverneur-Generaal in deze afgelegene bezittingen, zoozeer geschikt voor de invoering van zachtere en meer beschermende maatregelen, alsmede om aan de bedoelingen des Gouvernements meer vertrouwen, en aan de te maken bepalingen meer klem bij te zetten, eene gelegenheid aanbiedt, welke niet ongebruikt behoort te worden gelaten;

dat de bedoelde maatregelen, voor zooveel de Ambonsche eilanden aangaat (zullende de speciale belangen der Bandasche eilanden en voor de residentie Ternate op die plaatzen zelve nader in opzettelijke overweging komen) hoofdzakelijk bestaan:

in eene betere en vollediger zamenstelling des Bestuurs; 
eene meer doelmatige verdeeling van het grondgebied in het belang der ingezetenen, en byzonder ter bevordering van de gemakkelijkheid en veiligheid van derzelver onderling verkeer;

eene goede, gereede en onkostbare regtsbedeeling;

eene onherroepelijke afschaffing der noodlottige extirpatiën en daaraan verbondene dwangwetten, en een nauwkeurige en meer doelmatige van 's Gouvernements wege te houden zorg en toezigt tot bevordering van de culturen, inzonderheid van de kruidnagelen;

eene verligting van de heerendiensten en beperking derzelver tot volstrekte noodzakelijkheid, zoolang de omstandigheden niet zullen toelaten dezelve geheel op te heffen;

de afschaffing van allen dwangarbeid en verpligte leverantiën om niet, of voor al te geringe prijzen;

de afschaffing van de wreede en schier zonder doel geworden hongytogten, en de betere bescherming van de ingezetenen in derzelver handelsverkeer door meer behoorlijke en doelmatiger zamengestelde verdedigingsmiddelen;

in eene naauwkeurige omschrijving der regten en verpligtingen van de bevolking, van derzelver regenten en oudsten, met duidelijke bepalingen van hetgeen, inzonderheid ten aanzien der regenten, betrekking heeft tot derzelver afkomst, opvolging en verkiezing, en de grenzen hunner bevoegdheid in het aanwenden van middelen tot handhaving van politie, en in het beslissen van kleine huishoudelijke geschillen, zijnde de provisioneele instructie voor de regenten, gearresteerd den 15 Augustus 1818, in vele opzigten ondoelmatig, onvolledig en ongenoegzaam bevonden, terwijl ook meerdere der daarbij voorkomende bepalingen door de veranderingen, thans in het Bestuur der Ambonsche eilanden ontstaande, niet meer te pas kunnen komen; en eindelijk in eene eenvoudige, duidelijke en naar de begrippen en vatbaarheid der bevolking ingerigte openlijke bekendmaking van alle deze onderscheidene maatregelen als een onmiddelijk gevolg van de vaderlijke belangstelling des Konings in haar lot, en van de weldadige bedoelingen van het Gouvernement te haaren opzigte, met vermelding tevens van de billijke verwachting, welke het Gouvernement, als eene erkenning van dit goede, wederkerig van de bevolking koestert,

Is goedgevonden en verstaan:

(Zie Stbl. 1824, No. 19a). 